\title{
The Historical Literacy of Secondary School Pupils: A Case Study of the Concept Causation
}

\author{
Sonja Schoeman \\ Department of Curriculum and Instructional Studies, UNISA
}

\begin{abstract}
History education is about the development of the historical literacy of pupils, and, consequently, the understanding of historical concepts such as causation. The purpose of the study was to contribute to an understanding of what cognitive processes are involved in learners' causal explanation of historical events, and which teaching strategies could be implemented in classrooms to enhance the historical thinking and understanding of learners. Two explanatory research questions were formulated. A non-experimental research design involving quantitative data was used for this study. The systematic probability sampling technique was used to identify the sample of the study. Fifty respondents (five groups of ten) participated in the research project. A groupadministered questionnaire was used to collect the data. The data was analysed by means of descriptive statistical analysis. The study revealed that different groups of learners produced different historical explanations depending on their age and knowledge and experience of history. An exemplar causation lesson of how to engage pupils in real historical thinking and understanding was included.
\end{abstract}

\section{Introduction}

In re-framing the debate about the purpose, place and methodology of History education in secondary schools, the term historical literacy was a useful concept to apply. The concept in itself is insufficient, and only becomes effective if the elements of what constitutes historical literacy are identified. To become literate in history, learners need to build knowledge and understanding about the stories, questions and issues of history [1]. An aspect of the various developments in the teaching and learning of history, which have emerged since the evolution of the new history, was the emphasis on the importance of key concepts in history. The more sophisticated the pupils' understanding of these concepts when related to historical content is, the greater the depth of their historical understanding [2]. Samson [3] argues that the application of these concepts, or rules of thought, helps to turn information into historical knowledge. Even when pupils' recall of specific historical detail diminishes, the understanding that comes from the conclusion about the significance of events is the enduring educational outcome [3]. For this reason, the key concepts were also included in the South African national education policy documents for History published since 2002 [4].

A key element of learners' historical literacy is the understanding of concepts [1]. The problem of this study focuses on two issues, firstly, that the concept of causation is arguably the most complex of the key concepts; and secondly, how teachers might teach the concept to secondary school pupils in terms of real historical thinking and understanding. The concept causation is difficult to teach and it is not easy to make assumptions about the extent of pupils' understanding of cause and consequence [2]. Mulholland and Ludlow [5] and Shemilt [6] argue that it is the very complexity and contingency of the concept causation that was one of the major reasons why pupils “... frequently misconstrues even the most apparently self-evident features of the causality concept."

One of the chief conceptual challenges faced by pupils when teaching causation is mistaking events and facts for causes and consequences. Traditionally causes were dealt with as a list of information - any analysis that had been done was done by the teacher or the author(s) of the textbook, and not by the pupils. Pupils were presented with a list of causes and consequences of an event and committed these to their memory to reproduce for assessment. There was very little attempt to encourage pupils to think about the nature of the concept involved, and developing their historical understanding [7]. 
Mulholland and Ludlow [5] and Voss [7] confirm that: "... for many years, causes and effects of historical events were offered to learners in South African public schools as recipes and not as something to think about ....", and "... too often schools have dealt with causation in history uncritically .... ." Shemilt's [6] research on the teaching of the causes of historical events confirms the above statements: “... although learners could grasp the idea that a historical cause was something with the "power to make something else happen", they often "could not identify, articulate or understand the direct connection - the causal link - between cause and effect." The reason for this is according to the Report of the History/Archaeology Panel [4] and Shemilt [6], educators' and textbooks' portrayal of the causes of events as cut and dried and indisputable. Educators dictate or ask learners to copy the "recognised" causes of certain events. Textbooks also do not explain the connections between cause and effect [7].

Further identified challenges were that the pupils were only appreciating monocausal, rather than multicausal factors; not being able to appreciate the different significance of cause and consequences; not being aware of categories such as the social, political and economic; not being able to distinguish between long-, medium- and short-term cause and consequence; and failing to understand the complexity of motivation in history [2].

There have been critics of this traditional approach since the beginning of the $20^{\text {th }}$ Century. Some innovative History teachers saw the important methodological implications of not relying on the teacher to do all the intellectual work, and advocated that "... pupils themselves should be generalizing, analyzing, judging and explaining" [8]. For this reason, identifying the challenges faced by pupils should been seen as a means by which teaching solutions can be identified.

\section{Research questions and purpose of the study}

The following two explanatory research questions were formulated: RQ1: What cognitive processes are involved in pupils' causal explanation of historical events? and RQ2: Which teaching strategies can be included in South African History lessons to enhance the historical thinking and understanding of learners in terms of the concept causation?
Consequently, the purpose of the study was, firstly, to determine the cognitive processes involved in pupils' explanation of the causes of an historical event; and, secondly, to empower teachers to design a range of lesson activities to develop pupils' understanding of the key concept causation, and enhance their historical thinking. To this end, the following structure was used for the study: a literature review which contains the theoretical perspective of the study, and a clarification of the concepts and applicable cognitive development theories, followed by the outcomes of an empirical study of the cognitive processes involved in the causal explanation of an historical event, and, finally, conclusions which includes an exemplar causation lesson plan.

\section{Literature review}

\subsection{Constructivism as theoretical perspective of the study}

The use of constructivism is advocated as theoretical perspective for the teaching of the key concepts in History as it represents a break from the teaching and learning of History which search for the acquisition of knowledge that mirrors a singular reality of textbook-defined facts and concepts. A more flexible, culturally relativistic and contemplative perspective of reality is needed, where knowledge is constructed based on personal and social experience. Constructivism emphasises the active role of the individual pupil in the construction of knowledge, the primacy of social and individual experience in the process of learning, the realisation that the knowledge attained by the pupil may vary in its accuracy as a representation of an external reality, and that knowing has its roots in biological or neurological construction and social, cultural and language-based interactions [9].

The three main branches of constructivism are radical constructivism, social constructivism, and cognitive constructivism. An outline of the three different types of constructivism is presented below.

Radical constructivism emphasises the internal nature of knowledge, and embraces the philosophic tenet that while a reality external to the individual may exist, the true nature of the reality is not knowable to the individual as it is not yet part of his/her subjective construction. Knowledge then becomes the subjective construction of the individual, resulting from the cumulative experiences of the individual. This 
subjective construction implies that knowledge is not passively transmitted from the environment (classroom) to the individual (pupil), but that knowledge is the result of active cognising by the individual (pupil) for the purpose of satisfying some goal (thinking about the nature of the concept causation and the development of real historical understanding and literacy). The ultimate goal of knowing is the construction of internally coherent mental structures that are adaptive and lead to efficient and effective thinking and behaving.

Social constructivism emphasises the social nature of knowledge, and embraces the philosophic tenet that an individual cannot come to know reality in any other meaningful way as in terms of social interaction (group work activities). The social activity (group work) as source of knowledge emphasises language, culture and context (discussion, activities, subject content). For social constructivism, truth is determined between people who are collectively searching for truth in the process of their dialogic interaction.

Cognitive constructivism emphasises the external nature of knowledge, and embraces the philosophic tenet that an individual can come to know reality as it exists external to the individual, knowledge is objective, and the acquisition of knowledge is the (re)construction of external reality into internal mental structures (classroom presentation, learner activity, cognitive theories), [9].

In all three branches of constructivism, the teacher is not concerned with whether the pupils learn a set of textbook-defined facts and concepts, but whether the pupils' understanding are coherent and valid given the resources with which they have engaged (radical constructivism), the pupils' social interaction has resulted in consensus (social constructivism), and the pupils' have built mental structures that correspond to reality (cognitive constructivism), [9].

\subsection{Concepts historical literacy and causation}

The concept historical literacy entails a systematic process with particular sets of skills, attitudes and conceptual understandings that mediate and develop historical consciousness. Hence, historical literacy is not about a purposeless knowing of facts about the past, but about personal, social and political empowerment. It is also based upon a judicious balance between social expectations about what pupils should know about history and individual understandings and skills. The key elements of historical literacy are the knowing and understanding of past events and narratives, research skills, the language of history, historical concepts, Information and Communication Technology, the making of connections, contention and contestability, representational expression, moral judgements in history, applied science in history, and historical explanation [1].

Few concepts in academic history are more keenly debated than the concept causation. Most of the historical debate focuses upon the question: What caused these events to happen? One of the major reasons for the debate is that causation is rooted in contingency and uncertainty [10].

Scott [10] defines the concept causation as: $\ldots$ an understanding of the difference between long-term and short-term causes; an understanding that some causes are likely to be more important than other; an appreciation of the difference between, and the interdependence of, motivatory and enabling factors; and an understanding of the inter-relationship of different causatory factors.

\subsection{Cognitive development theories and historical inferences}

Piaget has identified four key stages in the cognitive development of children, which are characterised by changes in how they understand the world. During the first sensorimotor stage, from birth to age 2, the infants and toddlers acquire knowledge through sensory experiences and the handling of objects, and are not able to hold more than one perspective at a time. In the second preoperational stage, from age 3 to 6 , the child learns through pretend play, struggles with logic, taking the point of view of other people, and is bound by observable reality. In the third concrete operational stage, from age 7 to 11 , the child begins to think more logically, but the thinking is very rigid, and he/she is still struggling with abstract and hypothetical concepts. The fourth formal operational stage, from adolescence into adulthood, involves an increase in logic, the ability to use deductive reasoning, and the understanding of abstract ideas [11].

Piaget's [12] research findings on language and logic are the most appropriate to apply to inferential reasoning in history, and he explained a sequence in the development of argument. At the first level, the child is not concerned with 
interesting or convincing others, and leaps from a premise to an unreasonable conclusion in one bound. At the second level, the child attempts to communicate intellectual processes which are factual and descriptive, and show incipient logic that is not clearly expressed. This leads to a valid statement of fact or description, followed by a primitive argument in which the statement or opinion is followed by an implicit deduction. At the third level, the child attempts to justify and demonstrate assertion by using a conjunction (since, because, therefore), but does not succeed in expressing a logical relationship. He/she eventually arrives at genuine argument, through frequent attempts to justify his/her own opinion and avoids contradiction. As a result of an internal debate, he/she is able to use the conjunction because; and, correctly relate the argument to its premise. Finally, at the fourth level, the child cannot only use conjunctions, but also disjunctions, and can identify implications, and consider incompatible propositions. This is consistent with the view that pupils become increasingly able to make inferences about the past from historical sources.

There have been various studies relating Piaget's developmental levels to pupils' historical thinking. It was also found that three of the four levels can be revealed amongst a group of children of almost any age, because the nature of the evidence and the complexity of the questions influence the children's level of response. In the 1960s, children's responses to historical evidence were classified in terms of Piagetian levels by Peel [13].

Peel [13] identified a describer stage of unjustified and unqualified statements, a transitional stage of justified hypothesis and recognition of logical possibilities, and an explainer stage of weighed arguments using abstract propositions. He also demonstrated that, young children's ability to make inferences may be greater than Piaget suggested. He argued that the levels of thinking varied according to the nature of the questions asked and the child's interest and involvement. Very young children are capable of logical argument if they understood how to tackle the problem and were interested in it; consequently, logical thinking can exist from an early age, and becomes more complex through increased experience and memory. Piaget's own case studies also offer evidence that comments, suggestions and criticism make pupils aware of the elements in problem-solving, and can accelerate their progress [12].

\section{Empirical study}

A non-experimental research design involving quantitative data was used for this study.

\subsection{Data-collection instrument}

A group-administered questionnaire was developed to obtain data on the cognitive processes involved when pupils have to explain the causes of an historical event (Colonialism in Africa). Peel's [13] and Hallam's [14] model of pupils' historical conceptual development, and Carretero et al.'s [15] findings of a 1994 research project about causal explanation in history using different tasks were used in planning the questionnaire. According to the above researchers, age and expertise tend to have an influence on the way a pupil explains the causes of an historical event.

The questionnaire comprised two sections. The purpose of Section 1 of the questionnaire was to establish the ages of the respondents in order to determine if age plays a role when respondents have to explain the causes of an historical event. The following age groups were presented to the respondents: 14 to 15 years old, 16 to 17 years old, 18 to 19 years old, and 22 years and older. The respondents were requested to tick off their specific age in the applicable block. The above age groups were chosen as sample because of the views of Peel [13] and Hallam [14]. They pointed out that history is an abstract subject that cannot be understood at a stage well below the formal operational stage, 16,2 to 16,6 years. Only at the formal operational stage or so-called explanatory stage will pupils be able to make effective inferences from limited information and hypothesise in terms of motivation and causation.

The purpose of Section 2 of the questionnaire was to determine if expertise plays a role when respondents have to explain the causes of an historical event. The following ordinal question was presented to the respondents: "What caused colonialism in Africa?" In an effort to obtain a precise answer to the question, respondents were presented with six factors. Each factor could be considered as a possible cause of the historical event. Respondents had to rank the six factors according to the significance of each in the causation of the historical event, ranking the most important factor first and the least important factor sixth. The six factors were the intentional, ideological, economic, scientific-technological, political and strategic. The information provided with regard to the six factors is based on the main 
factors presented in textbooks [16] as explanation of the historical event. The decision to include only these six factors in the questionnaire was made after a study of the following theories of colonialism, namely, economic imperialism, European nationalism, the revisionist explanation and the strategic explanation [17]. "Colonialism in Africa" was chosen as the knowledge focus area for the research project because of its presence as a topic in the History curricula of primary and secondary public schools, pre-1998 as well as post-1998. All respondents would therefore have some tacit knowledge of the topic.

\subsection{Respondents}

The systematic probability sampling technique was used to identify the sample of the study. Fifty respondents (five groups of ten) participated in the research project. Three of the five groups comprised adolescents of the following age groups: 14 to 15 year-olds, 16 to 17 year-olds, and 18 to 19 year-olds. The adolescent respondents came from a public school in the Johannesburg West: D12 area. All the adolescent respondents were exposed to History instruction during their primary and/or secondary school careers. The two remaining groups comprised adults older than 22 years of age enrolled for the Postgraduate Certificate in Education (Senior Phase and FET) at a South African university: one group consisted of Learning Area Didactics Life Orientation students, with languages, psychology, biblical studies or religious studies as majors for their bachelor's degree; and the other group was made up of Subject Didactics History students, with history as major for their bachelor's degree. All the Learning Area Didactics Life Orientation students were exposed to History instruction during their primary school careers. The expertise (length and experience of History study) of the sample varied from informal or tacit knowledge to formal or extensive knowledge of the historical event. The adult respondents were from all over the province of Gauteng.

\subsection{Data-collection procedure}

Two months prior to the administration of the questionnaires, permission was obtained from all respondents. The questionnaires were administered during five sessions. It was done by the Johannesburg West: D12 office and the researcher respectively. A representative of the Johannesburg West: D12 office applied the questionnaires to the three adolescent groups. The questionnaires to the two adult groups were applied by the researcher herself. The procedure for both groups was identical. The respondents' anonymity was assured and voluntary participation in the research project was ascertained. A $100 \%$ response rate was obtained. The collected data was then prepared for analysis. The tabulated data was subjected to descriptive statistical analysis using mean ranking scores. Respondents' ranking of the causal factors was assessed on a scale of 1 to 6 . A high ranking of a factor was represented by a 1 and a low ranking of a factor was represented by a 6 . A mean score of 3.50 or higher was interpreted as a low ranking of a factor, and a mean score of less than 3.50 as a high ranking of a factor.

\section{Results}

Tables 1 and 2 (below) shows the rankings of the total sample $(\mathrm{N}=50)$ of the importance of the factors.

Table 1. Group mean rankings (M) and standard deviations (SD) of the importance of each factor in the explanation of colonialism in Africa: adolescent pupils

\begin{tabular}{|c|c|c|c|c|c|c|}
\hline \multirow[t]{3}{*}{ Causal factors } & \multicolumn{6}{|c|}{ Groups } \\
\hline & \multicolumn{3}{|c|}{14 to 15 year-olds } & \multicolumn{3}{|c|}{16 to 17 year-olds } \\
\hline & $M$ & SD & $\mathrm{N}$ & $M$ & SD & $\mathrm{N}$ \\
\hline Intentional & 1.60 & .78 & 10 & 2.15 & .89 & 10 \\
\hline Political & 4.45 & 1.16 & 10 & 3.55 & 1.52 & 10 \\
\hline Economic & 3.00 & 1.62 & 10 & 2.40 & 1.11 & 10 \\
\hline $\begin{array}{l}\text { Scientific- } \\
\text { technological }\end{array}$ & 2.60 & 1.58 & 10 & 3.15 & 1.65 & 10 \\
\hline Ideological & 4.15 & 1.15 & 10 & 4.70 & 1.06 & 10 \\
\hline Strategic & 4.90 & 1.05 & 10 & 4.85 & 1.08 & 10 \\
\hline
\end{tabular}

\begin{tabular}{|l|l|l|l|}
\hline Causal factors & \multicolumn{3}{l|}{ Groups } \\
\hline & 18 to 19 year-olds \\
\hline & $\mathrm{M}$ & $\mathrm{SD}$ & $\mathrm{N}$ \\
\hline & 2.50 & .56 & 10 \\
\hline Intentional & 3.65 & 1.16 & 10 \\
\hline Political & 1.70 & .72 & 10 \\
\hline Economic & 3.50 & 1.52 & 10 \\
\hline $\begin{array}{l}\text { Scientific- } \\
\text { technological }\end{array}$ & 5.20 & 1.08 & 10 \\
\hline Ideological & 4.15 & 1.07 & 10 \\
\hline Strategic & & & \\
\hline
\end{tabular}


Table 2. Group mean rankings (M) and standard deviations (SD) of the importance of each factor in the explanation of colonialism in Africa: adult graduates

\begin{tabular}{|c|c|c|c|c|c|c|}
\hline Causal factors & \multicolumn{6}{|c|}{ Groups } \\
\hline & \multicolumn{3}{|c|}{$\begin{array}{l}\text { Non-history } \\
\text { graduates }\end{array}$} & \multicolumn{3}{|c|}{ History graduates } \\
\hline & $M$ & SD & $\mathrm{N}$ & $M$ & SD & $\mathrm{N}$ \\
\hline Intentional & 2.60 & .58 & 10 & & 1.04 & 10 \\
\hline Political & 3.50 & 1.50 & 10 & & 1.03 & 10 \\
\hline Economic & 2.20 & .89 & 10 & & .88 & 10 \\
\hline $\begin{array}{l}\text { Scientific- } \\
\text { technological }\end{array}$ & 3.65 & 1.37 & 10 & & 1.35 & 10 \\
\hline Ideological & 5.10 & 1.13 & 10 & & 1.06 & 10 \\
\hline Strategic & 3.65 & 1.36 & 10 & 3.45 & 1.49 & 10 \\
\hline
\end{tabular}

\section{Discussion}

The study revealed that different groups of pupils produced different historical explanations depending on their age and knowledge and experience of history. The adolescent pupils considered the influence of specific persons in the historical event to be much more important than structural factors. A personalised understanding of history was therefore also common among the adolescents involved in the study. One of the main reasons for the intentional explanation of the adolescents might also be the cognitive development stage of the pupils: considering structural factors would imply a much more indepth knowledge of social and historical processes which most adolescent pupils in the concrete operational or descriptive stage of cognitive development are unable to achieve. The younger adolescent pupils who have attained the concrete operational or descriptive stage of cognitive development provided historical explanations that emerge from personal analogies and concentrated on personal rather than collective motivation or purpose. However, the older adolescent pupils who have already attained the formal operational or explanatory stage of cognitive development provided historical explanations of the rational purposive type that are more abstract. Tacit knowledge and familiarity with human action played a greater role in the adolescents' explanation of the historical event than historical skill.

The adult History graduates' explanation bear testimony of their formal operational or explanatory stage of cognitive development, and they used their extensive knowledge base of history to explain the causes of the historical event. Personal agents have almost no influence in their explanation, and the most influential factors were structural factors. The adult nonhistory graduates' explanation also bear testimony of their formal operational or explanatory stage of cognitive development. Their explanation showed awareness of personal actions as well as structural factors. They used their tacit knowledge and familiarity with human action as well as metacognitive knowledge to explain the causes of the historical event.

In a project conducted by Halldén [18] in the 1980s, he observed that a personalised understanding of history is common among many adolescents. According to Halldén [18], adolescents tend to consider the influence of specific persons in historical events to be much more important than abstract and nonpersonalised factors, such as political and social structures. He did however argue that the main reason for this could be that considering abstract issues would imply a much more in-depth knowledge of social and historical processes, which most adolescents are unable to obtain before they are 17 or 18 years of age. Bereiter and Scardamalia [19] conducted a research project in the 1990s regarding the different types of knowledge applicable when pupils have to explain an historical event. According to Bereiter and Scardamalia [19], in the case of younger pupils, tacit knowledge usually plays a greater role than historical skill, as these pupils commonly use their informal knowledge to explain the causes of an historical event. On the other hand, adult History graduates will use their formal knowledge or extensive knowledge base of history to explain the causes of an historical event; whilst adult non-history graduates use their tacit as well as meta-cognitive knowledge to explain the causes of an historical event.

\section{Conclusion and recommendations}

According to Walsh [20], given the purpose of history as a record of human events in historical context, the aim of History teaching is to help pupils understand and explain such events. For teachers to help pupils to understand and explain historical events, they should have a clear idea of what constitutes historical explanation, at which level to present the historical events and seek historical explanation, and of how to induce the ability in pupils. Evans [21] argued that while pupils may be capable of given the "becauses" of events, what "counts in school history" has to be learned. According to Newton and Newton [22], pupils learn "what counts" from repeated exposure to it and through the teacher's guidance. 
Given that pupils have this guidance, there are still requisites that facilitate or enable a particular historical understanding: for explanatory understanding pupils have to construct an understanding that incorporates the reasons and intentions involved in the action [23].

Causation can be both the easiest and one of the most difficult historical skills to teach. If causation is taught with the aim to let pupils know the reasons why an event took place, then teaching it becomes relatively easy. The reasons are given to the pupils, who are then asked to comprehend and remember them. However, if the aim is to engage the pupils in real historical thinking, it is much more demanding [24].

In the remaining paragraphs of this section, teachers of history are provided with an exemplar lesson of how to teach the concept of causation to engage pupils in real historical thinking. The aim of the lesson is to:

- identify a historical topic which can best serve the teaching of causation

- name the learning objectives for exploring causation

- employ possible approaches to stimulate pupils' interest in learning about causation

- formulate an enquiry question to develop pupils' causal reasoning

- provide the rationale for the knowledge necessary to develop pupils' causal reasoning and to use different teaching strategies to provide this knowledge

- identify the role of the teacher in developing pupils' causal reasoning [24].

The topics for causation lessons are usually major events in history such as wars or revolutionary change. An example of such a topic is The French Revolution. The latter provides a complex web of causes which can be traced back over many years prior to the event.

Having identified the topic for an exploration of the concept causation, it is crucial to consider what exactly the pupils have to learn about causation. Some objectives are to:

- know that there are reasons why the event happened

- $\quad$ highlight the causes from a narrative account

- $\quad$ establish the links between causes

- organise the causes into categories such as social, economic, political and intellectual

- distinguish between the long-term (trends) and short-term (triggers) causes of an event

- arrange the causes into a hierarchy of importance.

With the topic and objectives decided, the question of which aspects will have to be included in a causation lesson on the French Revolution has to be addressed. The main objective may be to enable the pupils to identify and classify the reasons for the French Revolution [24].

An effective way to introduce the concept causation to pupils is the cut-off-image starter activity. Pupils are presented with a print from an English engraving published in 1798 of the execution of Louis XIV (1793), but with the central scene blank. It is an effective strategy to begin teaching the concept causation with an event from the end of the story and then work back to explore why it took place. The pupils need to see the consequences of a chain of events to help them to focus on what they will be asked to explain. In order to complete this task, the pupils have to study the source and look for clues, which might help them to speculate as to what is happening in the picture. In addition, they will have to draw on their prior knowledge of the event.

The starter activity should create a problem for the pupils to solve: Why was it that a king, who normally was the person who gave the orders for someone to be executed, was executed? A list of questions which could focus the enquiry around causal reasoning is: What were the causes of the French Revolution? What were the key events leading up to the Storming of the Bastille on 14 July 1789? and How and why did the French Revolution happen? [24].

Before any analysis of causation can take place, the pupils need to understand the narrative of the French Revolution, and acquire a strong chronological factual base for this purpose. The most common way in which the historical content can be covered is a written narrative text taken from a textbook. The objective is not for the pupils to know every event leading up to the revolution, but to appreciate how certain events led to a deterioration in the relations between the king and the people of France.

The teaching strategies will depend on the learning objectives. For a French Revolution lesson, the main objectives will be to enable the pupils to:

- identify possible causes for the breakdown in the relations between Louis XVI and the third estate, and

- suggest possible ways of categorising the causes of the French Revolution.

To achieve the first objective, the pupils will have to re-read the narrative text and underline or highlight the phrases related to the possible reasons. To achieve the second objective, the 
main teaching strategy could be a card sort activity. This is where individual reasons for an event are written on separate sheets of paper and the pupils have to classify them and move the cards to create patterns and orders. However, the success of the card sort activity is based upon the pupils' discussion of the possible links [24]. The next step is to decide what pupils will do once the cards have been sorted. The most common classification for the French Revolution is to identify the social, economic, political and intellectual causes of the revolution, and to consolidate the underlying reasons for the revolution. The problem is that certain events, such as absolute power can be classified under more than one category.

This can be overcome by asking the pupils to place their cards into a Venn diagram such as illustrated in Figure 1 below.

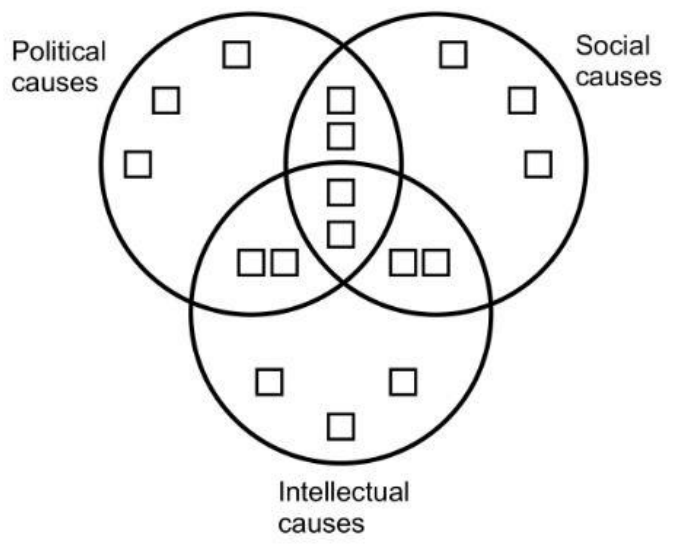
Figure 1. Venn diagram of possible reasons for
the French Revolution, 1789

Once the Venn diagram has been completed, the pupils can either complete an extended writing activity with the categories as paragraphs, or in groups of six explain their diagrams to the class as a whole [24].

Hence, teaching any historical skill is not about the teachers designing activities and assuming that in doing their teaching, that the pupils will develop real historical understanding. Within a constructivist classroom through their explanation (cognitive development theories and historical inferences) and exposition (historical concepts) skills teachers have to scaffold the pupils' to real historical thinking and understanding (historical literacy). This study was an attempt to improve the historical literacy of pupils in public school classrooms, and to serve as an introduction to further research in this regard.

\section{References}

[1] National Center for History Education, Historical Literacy, Available:

www.hyperhistory.org./images/assets/pdf/literacy.pdf. (Accessed on 10 November 2013), 2010.

[2] Haydn, T., J. Arthur and M. Hunt, Learning to teach History in the Secondary School, Routledge, London, New York, 1997.

[3] Samson, C., Concepts, Skills and Content: A Development Approach to the History Syllabus, In: Portal, C. (ed), The History Curriculum for Teachers, Lewis, Falmer Press, London, 1987.

[4] Department of Basic Education, CAPS Curriculum Assessment Policy Statement History, DoE, Pretoria, 2012; Department of Education, Report of the History/Archaeology Panel, DoE, Pretoria, 2000; Department of Education, Educator's guide to phase OBE into FET 2002-2005, Government Printer, Pretoria, 2002; Department of Education, National Curriculum Statement. Grades 10-12 History, DoE, Pretoria, 2002.

[5] Mulholland, R., and H. Ludlow, Teaching the past for the future, Perskor, Johannesburg, Cape Town, 1992.

[6] Shemilt, D., History 13-16. Evaluation Study. Schools Council History Project, Holmes McDougall, Edinburg, 1980.

[7] Voss, J.F., Toward a New Science of Instructional programmatic Investigations in Cognitive Science and Education - Argument, Inference and Learning, Available:

http://www.ed.gov/pubs/instscience/chap3e.htmol. (Accessed on 5 April 2013), 1993.

[8] National Curriculum Council, Teaching History at Key Stage 3, Continuum, York, 1993.

[9] S. Schoeman, "Presentation technology as a mediator of learners' retention and comprehension in the history classroom", Yesterday\&Today, 9, Sciello, Potchefstroom, 2013, p. 67.

[10] Phillips, R., Reflective teaching of History 11-18, Continuum studies in Reflective Practice and Theory, Continuum, London, New York, 2002.

[11] Cooper, H., Historical thinking and Cognitive development in the teaching of History, In: Boudillon, H., (ed), Teaching History, The Open University, London, New York, 1994. 
[12] Piaget, J., The Language and Thought of the Child. Routledge, London, 1926; Piaget, J., Moral Judgment and the Child, Kegan Paul, London, 1932.

[13] Peel, E.A., Some Problems in the Psychology of History Teaching, In: Burston, W.H., and D. Thompson, (ed), Studies in the nature and teaching of history, RHP, London, 1967.

[14] Hallam, R.N., Piaget and Thinking in history. In: Ballard, M. (ed), New Movements in the study and teaching of History, Temple Smith, London, 1970.

[15] Carretero, M., L. Jacott, M. Limón, A. LopezManjón, and J.A. León, Causal explanations about different historical events, Lawrence Earlbaum, Hove, UK, 1994.

[16] Dugmore, C., R. Mulholland, R. Nussey, R. Siebörger, and L. Torr, Making History Grade 8. Standard 6, Heineman, Johannesburg, 1999.

[17] Seleti, Y., C. Dyer, L. Naidoo, J. Nisbet, M. Roberts, C. Saunders, and G. Clacherty, Looking into the Past, Grade 11. Maskew, Miller, Longman, Cape Town, 2000.

[18] O. Halldén, "Learning History", Oxford Review of Education, 1986, pp. 53-66.

[19] Bereiter, C., and M. Scardamalia, Surpassing ourselves: An inquiry into the nature and implications of expertise, Open Court, Chicago, 1993.

[20] Walsh, W.H. An introduction to the philosophy of history, Hutchinson, London, 1971.

[21] Evans, R.J., In Defence of History, Grant, London, 1977.

[22] D.P. Newton, and L.D. Newton, "Knowing what counts as understanding in different disciplines: Some ten-year-olds conceptions", Educational Studies, 1999, pp. 35-54.

[23] Benton, T., and I. Craib, Philosophy of Social Science. The philosophical foundations of social thought, Palgrave, Hampshire, 2001.

[24] Chamber, C., Teaching causal reasoning, In: Hunt, M. (ed), A Practical Guide to Teaching History in the Secondary School, Routledge, New York, 2007. 